\title{
Does Inbreeding Affect Tolerance to Inflorescence Damage in Mimulus guttatus?
}

\author{
Andrew C. McCall ${ }^{1, *}$ and David E. Carr ${ }^{2}$ \\ ${ }^{1}$ Department of Biology, Denison University, Granville, OH 43023, USA \\ ${ }^{2}$ Blandy Experimental Farm, University of Virginia, 400 Blandy Farm Lane, Boyce, VA 22620, USA
}

\begin{abstract}
Inbreeding in plants causes various declines in fitness estimates across many species and may also affect adaptive phenotypic plasticity, as observed in tolerance to herbivory. Although there are a growing number of studies looking at this effect, there are still not enough to make general conclusions about the relationship between homozygosity and tolerance or resistance. In this work, we examined whether drastic herbivory, destruction of the flowering apex, was affected by inbreeding in three populations of Mimulus guttatus. We found that inbreeding increased tolerance to simulated herbivory in one population, had no effect on tolerance in another, and decreased tolerance in a third. These results point to the importance of the underlying genetic histories of individual populations, which are the fodder for the action of inbreeding. It may be difficult to find consistent effects of inbreeding on plastic traits like tolerance because of the relatively unpredictable relationship between heterozygosity and plasticity in general.
\end{abstract}

Keywords: Inbreeding, overcompensation, inbreeding depression, Mimulus.

\section{INTRODUCTION}

Inbreeding depression is an important phenomenon that often reduces the fitness of individuals in a population. The direct effects of inbreeding depression on plant fitness or components of fitness are well known. For example, inbreeding in plants often reduces flower, fruit, seed number, or seedling survival rates (Crnokrak and Roff 1999). This is usually interpreted as the action of recessive deleterious alleles masked in the heterozygote state but that affect phenotypes when two copies of the same allele in diploids (Charlesworth and Charlesworth 1987).

Recent work has investigated how inbreeding interacts with the biotic environment. For example, misshapen or smaller flowers caused by inbreeding can result in less pollination service than in outcrossed flowers (Ivey and Carr 2005). Interactions with inbreeding and herbivores have also been documented. For example, plant populations often have some level of resistance to herbivores, depending on past selection histories or drift (e.g. Muola et al. 2010). This resistance may decline in inbred plants versus outcrossed plants (Hayes et al. 2004, Stephenson et al. 2004), or may not vary at all between inbred and outcrossed lines (NuñezFarfán et al. 1996).

Inbreeding depression may also affect tolerance, a response that a plant exhibits to limit the effects of herbivore damage (Nuñez-Farfán et al. 2007). In some studies, tolerance was higher in outcrossed plants (Schoen 1983, Carr and Eubanks 2002), while in others, the effects of inbreeding

*Address correspondence to this author at the Department of Biology, Denison University, Granville, OH 43023, USA; Tel: 1-740-587-8554;

Fax: 1-740-587-5634; E-mail: mccalla@denison.edu on tolerance depended on the herbivore under scrutiny (HullSanders and Eubanks 2005). Still others have shown that in $14-43 \%$ of family lines of Mimulus guttatus inbreeding decreased tolerance, but in the remaining lines inbreeding either had no effect on tolerance or actually increased tolerance (Ivey et al. 2004). Indeed, a population's tolerance response to inbreeding may depend on selfing rates that, if high, could lead to purging of deleterious alleles (Ohta and Cockerham 1974) or to different rates of mutations. To date, no consensus can be drawn from these data either because of small number of studies.

Most of the work done on inbreeding and tolerance has involved leaf herbivory, which is only one type of damage that plants can suffer. Our study seeks to expand research into how tolerance and inbreeding interact by considering a different, but common, type of damage to plants - grazing of the inflorescence meristem. Workers studying tolerance to herbivory in inbred versus outcrossed plants have often used less drastic types of damage, which may have led to the mixed results we note above. Complete removal of a bolting inflorescence may thus help show more dramatically how inbreeding affects tolerance, if there is an effect at all. Our questions in this experiment are: 1) Does inbreeding affect tolerance to apical damage? and 2) Do different populations with different floral characteristics react differentially to inbreeding, apical damage, or their joint effects?

\section{METHODS}

Mimulus guttatus DC. (Phrymaceae Schauer) is distributed across western North America and is considered a naturalized exotic in eastern North America and Canada (Vickery 1974). Some populations that have moist areas throughout the year have perennial individuals whereas drier 
Table 1. Distribution and Floral Characteristics of the Three Populations in this Study

\begin{tabular}{|c|c|c|c|}
\hline Population & Latitude/Longitude & Mean Corolla Width (mm) ( \pm 1 S.E.) & Mean Stigma-Anther Separation $(\mathrm{mm})( \pm 1$ S.E. $)$ \\
\hline DP & $\begin{array}{c}37^{\circ} 42^{\prime} \\
120^{\circ} 26^{\prime}\end{array}$ & $24.6(1.09)$ & $4.8(0.22)$ \\
\hline M13 & $\begin{array}{l}38^{\circ} 33^{\prime} \\
122^{\circ} 22^{\prime}\end{array}$ & $19.1(0.69)$ & $3.5(0.17)$ \\
\hline RL & $\begin{array}{c}38^{\circ} 40^{\prime} \\
122^{\circ} 17^{\prime}\end{array}$ & $21.5(1.24)$ & $4.0(0.35)$ \\
\hline
\end{tabular}

environments generally support annual plants (Dole 1992). The plant initially produces many perfect, zygomorphic flowers on a raceme, with two flowers produced at each flowering node. The corollas vary in size between $20 \mathrm{~mm}$ to $30 \mathrm{~mm}$ in width and are sometimes spotted with red pigment (Carr and Eubanks 2002, A.M. pers. obs.). Herbivores on $M$. guttatus include the meadow spittlebug (Philaenus spumarius), larvae of the common buckeye butterfly (Junonia coenia), and an unknown mammalian herbivore that eats entire flowering shoots in some California populations (D. Carr, pers. obs.).

To investigate how inbreeding affects tolerance to inflorescence damage in $M$. guttatus, we first produced inbred and outcrossed lines using three different populations of $M$. guttatus. The three populations were M13 $\left(38^{\circ} 33^{\prime} \mathrm{N}\right.$, $\left.122^{\circ} 22^{\prime} \mathrm{W}\right)$ and $\mathrm{RL}\left(38^{\circ} 40^{\prime} \mathrm{N}, 122^{\circ} 17^{\prime} \mathrm{W}\right)$ from Napa County, and DP $\left(37^{\circ} 42^{\prime} \mathrm{N}, 120^{\circ} 26^{\prime} \mathrm{W}\right)$ from the foothills of the Sierra Nevada in Calaveras County. These populations were chosen because they varied in their corolla widths and stigma-anther separation, which could affect the amount of inbreeding they experienced (Table 1). For example, M13 has smaller corollas and a smaller stigma-anther separation, indicative of a more selfing population while DP has larger corollas and a more pronounced stigma-anther separation, suggesting a more outcrossing population (Dole 1992).

Field collected seed from each population was brought to the greenhouse at Blandy Experimental Farm in Virginia. One seedling from each of ten maternal families within a population was transplanted to a greenhouse and used for hand pollinations. Each plant within a population served once as a pollen donor and once as a pollen recipient for the outbred breeding treatments. Mates were selected at random from the available flowering plants. Each plant was also selfpollinated. Hand-pollinations were performed by first plucking an anther from the pollen donor using a forceps. The anther was rubbed directly onto a stigma of the pollen recipient and fruit were collected as they began to dehisce approximately 3 weeks later.

After seeds of the two mating types were produced, we randomly chose 40 seeds among all maternal lines from inbred plants and 40 seeds from the outcrossed plants for each population. These seeds were then planted in $6.35 \mathrm{~cm}$ square pots using Premier Promix (Premier Horticulture, Quakertown, PA 18951) soil. Each seed was then assigned an inflorescence damage type so that half of the inbred plants were to receive damage and half of the outcrossed plants were to receive damage. In total, 240 seeds were initially planted in the experiment ( 3 populations $\times 20$ plants per mating type/damage combination). Plants were bottom- watered every other day and grown under a $16 \mathrm{~h}$ light: $8 \mathrm{~h}$ dark regime.

When the seedlings germinated, we measured the length of the first true leaf at full expansion and the number of true leaves after three weeks of growth. We measured these variables to correct for initial size differences among plants prior to application of the damage treatment. We combined these variables by performing a principle component analysis and extracting the values for the first principle component for use as a single covariate in the final model. As the plants began to bolt, but before any flowers were produced, we cut each inflorescence so that $2 \mathrm{~cm}$ of the stem was left. We then counted the number of flowers subsequently produced by each plant throughout the experiment. In response to the damage treatment, most plants produced additional racemes from the base of the plant.

We used an ANCOVA model to determine whether our treatments had an effect on fitness. This model included the number of flowers produced throughout the growing period as the dependent variable, and the mating type, the damage treatment, and the population as fixed independent variables. We performed a Box-Cox transformation on the total flower number in order to reduce heteroscedasticity from the model. Maternal family nested within population and block within the greenhouse were considered random effects. The principle component score for initial plant size was used as covariate in the model. We ran a fully crossed model that included all of the interactions among the independent variables. On inspection of interaction effects, we then ran appropriate reduced models with mating type and damage treatment fully crossed within each population. All statistics were performed in JMP v 8.02 (SAS Institute, Cary NC, USA).

\section{RESULTS}

In the initial model, there was no significant random block effect (mean variance component $=249.08,95 \% \mathrm{CI}$ : 594.62-1092.79), but a highly significant effect of the initial size of the plant as a covariate (Table 2). There was a significant random effect of family nested within population (mean variance component $=2655.11$, 95\% CI: 66.445243.77). There was a significant three-way interaction (see Table 2) such that the significance of the interaction between damage and mating type depended on the population under consideration.

We then considered the two-way damage by mating type interaction within each population. In DP, there was a significant damage by mating type interaction $\left(F_{1,54}=9.08\right.$, 
Table 2. Results of a Mixed-Model ANOVA with Total Number of Flowers as the Response Variable. Significant Values are Marked in Bold

\begin{tabular}{|c|c|c|c|}
\hline Fixed Effect Source & $F$ Ratio & df & $P$ \\
\hline Initial size & 31.14 & 1 & $<0.0001$ \\
\hline Population & 2.87 & 2 & 0.075 \\
\hline Mating type & 9.78 & 1 & 0.002 \\
\hline Damage treatment & 32.83 & 1 & $<0.0001$ \\
\hline Pop x Mating & 4.51 & 2 & 0.012 \\
\hline Pop x Damage & 4.29 & 2 & 0.015 \\
\hline Mating x Damage & 0.50 & 1 & 0.482 \\
\hline Pop x Mating x Damage & 6.36 & 2 & 0.002 \\
\hline
\end{tabular}
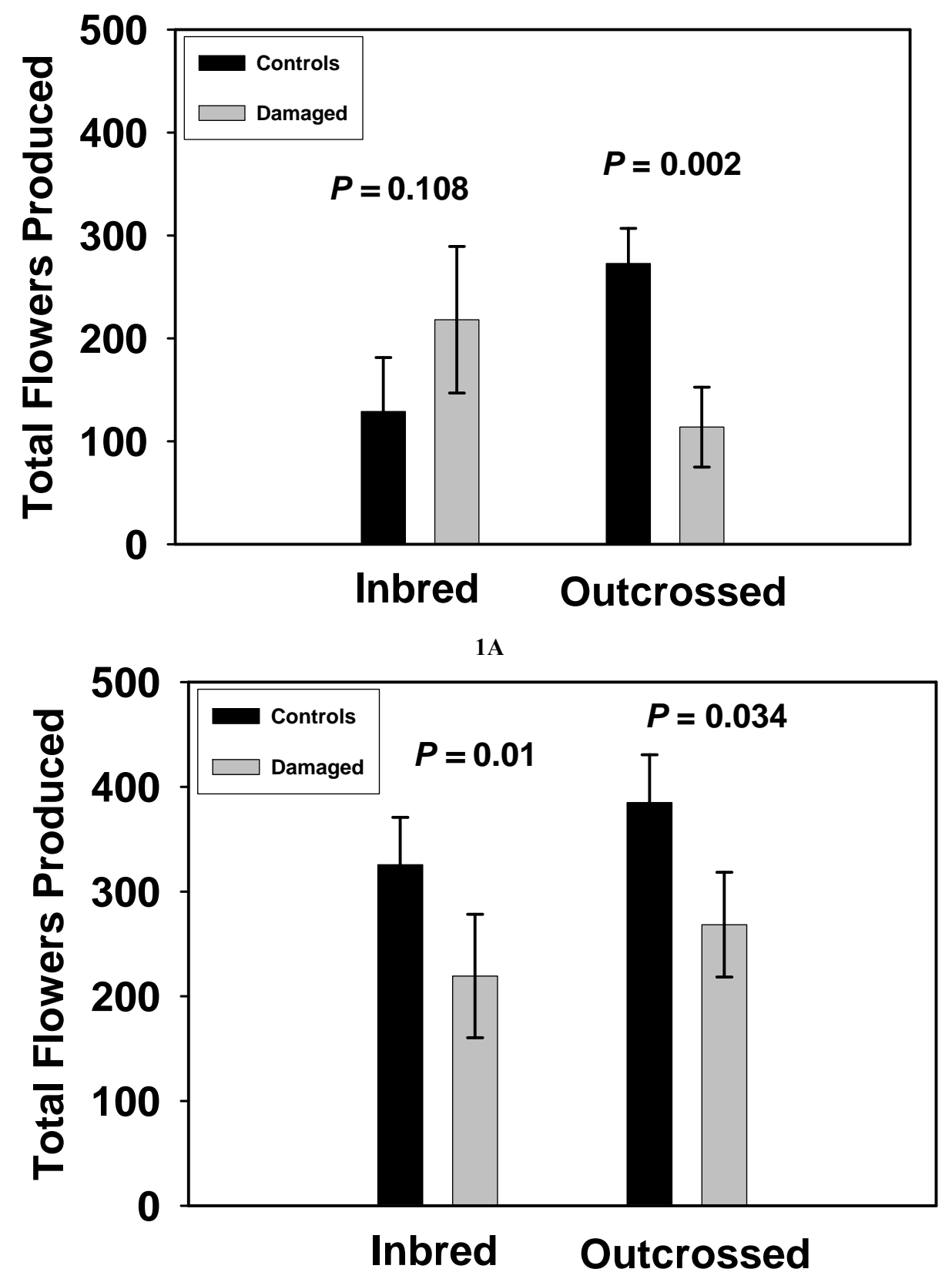


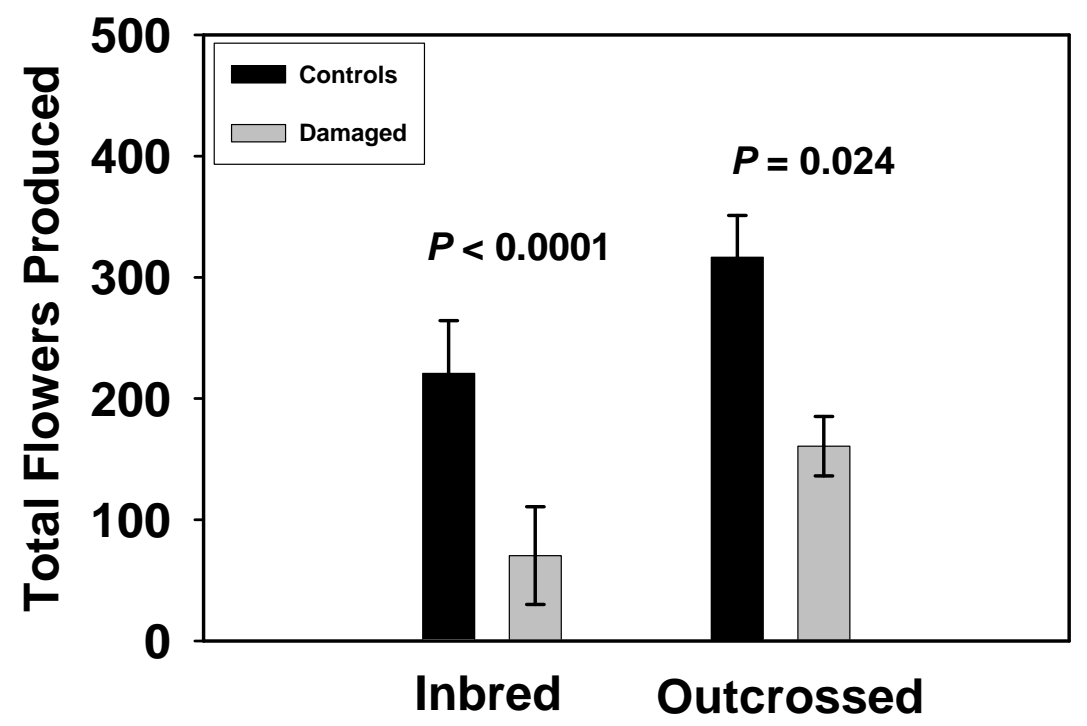

$1 \mathrm{C}$

Fig. (1). Results of two-way ANOVAs with mating type and damage treatment as crossed effects in the DP (1A), M13 (1B), and RL (1C) populations. There were significant interaction effects for DP and RL, but not for M13. $P$ - values above bars refer to the comparison between damage treatments within each mating type. Bars represent mean numbers of flowers produced \pm 1 S.E.M.

$P=0.004)$ such that there was no significant difference between the damage treatments within the inbred plants $\left(F_{1,46}=2.68, P=0.108\right.$, Fig. 1A $)$ and a significant effect of damage within outcrossed plants $\left(F_{1,46}=10.41, P=0.002\right.$, Fig. 1A). Within the outcrossed plants, there was a $75 \%$ reduction of flower production when the inflorescence was damaged. In M13, there was no significant damage by mating type interaction $\left(F_{1,69}=0.058, P=0.81\right.$, Fig. 1B), but there was a marginally significant main effect of mating type $\left(F_{1,69}=3.83, P=0.055\right)$ and a significant main effect of damage $\left(F_{1,69}=12.086, P=0.0009\right)$. Inbreeding caused a reduction of approximately $14 \%$ in flower number and artificial damage caused a decrease in flower number of about 32\% (Fig. 1B). In the RL population there was a significant damage by mating type interaction $\left(F_{1,64}=5.88\right.$, $P=0.019$ ) such that there was a highly significant difference between the damage treatments within the inbred plants $\left(F_{1,56}=24.87, P<0.0001\right.$, Fig. 1C) and a moderately significant effect of damage within outcrossed plants $\left(F_{1,56}=\right.$ $5.39, P=0.024$, Fig. 1C). Damage decreased flower number in both mating treatments, but the decrease was significantly greater in the inbred plants. Within the outcrossed plants, damage reduced flower number by approximately $49 \%$, whereas the decrease was approximately $56 \%$ within the inbred plants (Fig. 1C).

\section{DISCUSSION}

We found that the combined effects of damage and mating varied within the different populations. In each population, the level of tolerance to damage between inbred and outcrossed plants was qualitatively different from other populations. In one population, DP, there was no evidence that inbreeding affected tolerance while tolerance to damage in outcrossing plants was low. This was unexpected because this population had floral characteristics of a more outcrossing population and we might expect that inbreeding would have a large negative effect on tolerance due to the exposure of deleterious alleles. In another population, M13, the level of tolerance to damage was similar in both inbred and outcrossed plants. This particular population had floral characteristics suggesting higher rates of self-fertilization, so it is possible that some deleterious alleles had been purged from the population, as has been suggested for some family lines in M. guttatus (Dudash et al. 1997). In the third population, RL, both inbred and outcrossed plants suffered flower loss with damage, but inbred plants had less tolerance to damage than the outcrossed plants. As this population was intermediate in its floral characteristics, our results support the idea that more outcrossing may result in a greater cost to inbreeding when comparing RL to M13, but not when comparing RL to DP.

It is not surprising that these populations responded to the treatments in different manners. Different populations inevitably accrue different alleles over time through random events and different selection regimes (Schultz and Willis 1995). Thus, when inbreeding occurs, different alleles in different populations will be exposed, resulting in variation in the effects of inbreeding. Even though our experimental manipulation used very standardized levels of damage, the different population histories probably resulted in the varied mating system by damage effects we observed.

One of the populations we studied, M13, has been the subject of other experiments involving inbreeding and tolerance to spittlebugs (Ivey et al. 2004) and cucumber mosaic virus (Carr et al. 2003). Carr et al. (2003) found that inbred plants in this population were neither more nor less tolerant to CMV than outcrossed plants when either the number of flowers produced or biomass were considered as measures of fitness. There was similarly no significant effect of inbreeding on tolerance to spittlebugs in this population when five different measures of fitness were used as response variables (Ivey et al. 2004). In the same population, however, Carr and Eubanks (2002) found that inbreeding decreased tolerance to spittlebug damage when aboveground 
biomass and flower production were used as fitness measures. These mixed results would suggest that the effects of mating system on tolerance are relatively labile, depending on the type of fitness measure used or even the year in which a study was conducted.

In general, our results show that the effects for both tolerance and the effects of stress on inbreeding depend on the population under study and thus the effects of selection for resistance traits may differ across populations. In some populations, like DP, there may be little selection for resistance in the face of severe apical damage among inbred plants because of their high degree of tolerance. Similarly, outcrossed plants in this population may be under pressure to resist herbivores because of their low resistance. In another population, RL, the situation was reversed, leading to the hypothesis that selection for resistance traits could possibly be stronger in inbred versus outcrossed plants. Because of these differences, it is difficult to predict the specific response to damage under different mating regimes across populations. Other workers have even shown that different families within $M$. guttatus populations differ in their responses to damage under different mating systems (Ivey et al. 2004).

All of these varied results suggest that hypotheses that predict either increased or decreased tolerance in the face of inbreeding may be too simple to explain most ecological systems. While it is true that inbreeding generally decreases direct fitness measures like fruit or flower production, it seems difficult to make generalizations about stressors like herbivory that can be intermittent in nature. Because tolerance to herbivory is a mechanism that can be considered a type of adaptive phenotypic plasticity, the problems with predictions of a consistent relationship between tolerance and inbreeding may stem from problems with general hypotheses about the relationship between inbreeding and plasticity.

For example, the 'developmental stability hypothesis' (Pederson 1968) predicts that reduced heterozygosity results in less developmental stability and thus increased sensitivity to stresses. This idea has not been supported by the handful of experiments that have tested plasticity in other environmental changes besides herbivory. For instance, Schlicting and Levin (1986) found that up to three rounds of inbreeding had little consistent effects on plasticity in response to low water, leaf removal, or restricted root space in Phlox drummondii. Similarly, Quisenberry and Kohel (1971) found that inbred lines of cotton were not more plastic than outcrossed lines. In a more recent experiment on Mimulus ringens, O'Halloran and Carr (2010) found that inbreeding had little effect on plasticity in response to changes in soil moisture. Thus the lack of consistent effects of inbreeding on traits based on plasticity, like tolerance to herbivory, may be due to the underlying ambiguous predictions that can be made between plasticity in general and inbreeding.

In conclusion, we show that increased tolerance to inflorescence damage depends on what population is under consideration for M. guttatus. These results also indicate that inbreeding may not necessarily result in reduced fitness under more stressful conditions. The inbreeding and selective pressure histories of particular populations may instead be at least as important as discrete bouts of inbreeding in determining how inbred plants react to different stresses. We recommend that as much environmental and inbreeding information about different populations be taken into account when studying the effects of inbreeding in different conditions.

\section{CONFLICT OF INTEREST}

The authors confirm that this article content has no conflicts of interest.

\section{ACKNOWLEDGEMENTS}

We thank the Blandy Experimental Farm for support during this project. We would also like to thank one anonymous reviewer for their helpful comments on earlier versions of this work.

\section{REFERENCES}

Armbruster, P \& Reed, DH (2005) Inbreeding depression in benign and stressful environments. Heredity, 95, 235-42.

Bello-Bedoy, R \& Nunez-Farfan, J (2011) The effect of inbreeding on defence against multiple enemies in Datura stramonium. Journal of Evolutionary Biology, 24, 518-30.

Carr, DE \& Eubanks, MD (2002) Inbreeding alters resistance to insect herbivory and host plant quality in Mimulus guttatus (Scrophulariaceae). Evolution, 56, 22-30.

Carr, DE, Murphy, JF \& Eubanks, MD (2003) The susceptibility and response of inbred and outbred Mimulus guttatus to infection by Cucumber mosaic virus. Evolutionary Ecology, 17, 85-103.

Charlesworth, D \& Charlesworth, B (1987) Inbreeding depression and its evolutionary consequences. Annual Review of Ecology and Systematics, 18, 237-68.

Crnokrak, P \& Roff, DA (1999) Inbreeding depression in the wild. Heredity, $83,260-70$

Dole, JA (1992) Reproductive assurance mechanisms in three taxa of the Mimulus guttatus complex (Scrophulariaceae). American Journal of Botany, 79, 650-9.

Dudash, MR, Carr, DE \& Fenster, CB (1997) Five generations of enforced selfing and outcrossing in Mimulus guttatus: inbreeding depression variation at the population and family level. Evolution, 51, 54-65.

Hayes, CN, Winsor, JA \& Stephenson, AG (2004) Inbreeding influences herbivory in Cucurbita pepo ssp texana (Cucurbitaceae). Oecologia, 140, 601-8.

Hull-Sanders, HM \& Eubanks, MD (2005) Plant defense theory provides insight into interactions involving inbred plants and insect herbivores. Ecology, 86, 897-904.

Ivey, CT \& Carr, DE (2005) Effects of herbivory and inbreeding on the pollinators and mating system of Mimulus guttatus (Phrymaceae). American Journal of Botany, 92, 1641-9.

Ivey, CT, Carr, DE \& Eubanks, MD (2004) Effects of inbreeding in Mimulus guttatus on tolerance to herbivory in natural environments. Ecology, 85, 567-74.

Muola, A, Mutikainen, P, Laukkanen, L, Lilley, M \& Leimu, R (2010) Genetic variation in herbivore resistance and tolerance: the role of plant life-history stage and type of damage. Journal of Evolutionary Biology, 23, 2185-96.

Nunez-Farfan, J, Cabrales-Vargas, RA \& Dirzo, R (1996) Mating system consequences on resistance to herbivory and life history traits in Datura stramonium. American Journal of Botany, 83, 1041-9.

Nunez-Farfan J, Fornoni J \& Luis-Valverde, P (2007) The evolution of resistance and tolerance to herbivores. Annual Review of Ecology, Evolution and Systematics, 38, 541-66.

O'Halloran, LR \& Carr, DE (2010) Phenotypic plasticity and inbreeding depression in Mimulus ringens (Phrymaceae). Evolutionary Ecological Research, 12, 617-32.

Ohta, T \& Cockerham, CC (1974) Detrimental genes with partial selfing and effects on a neutral locus. Genetics Research, 23, 191-200.

Pederson, DG (1968) Environmental stress heterozygote advantage and genotype-environment interaction in Arabidopsis. Heredity, 23, 127-36.

Quisenberry, JE \& Kohel, RJ (1971) Phenotypic stability of cotton. Crop Science, 11, 827-9. 
Schlichting, CD \& Levin, DA (1986) Effects of inbreeding on phenotypic plasticity in cultivated Phlox. Theoretical and Applied Genetics, 72, 114-9.

Schoen, DJ (1983) Relative fitnesses of selfed and outcrossed progeny in Gilia achilleifolia (Polemoniaceae). Evolution, 37, 292-301.

Schultz, ST \& Willis, JH (1995) Individual variation in inbreeding depression: the roles of inbreeding history and mutation. Genetics, $141,1209-23$.
Stephenson, AG, Leyshon, B, Travers, SE, Hayes, CN \& Winsor, JA (2004) Interrelationships among inbreeding, herbivory, and disease on reproduction in a wild gourd. Ecology, 85, 3023-34.

Vickery, RK (1999) Remarkable waxing, waning, and wandering of populations of Mimulus guttatus: an unexpected example of global warming. Great Basin Naturalist, 59, 112-6.

Received: October 26, 2012

Revised: December 25, 2012

Accepted: December 28, 2013

(C) McCall and Carr; Licensee Bentham Open.

This is an open access article licensed under the terms of the Creative Commons Attribution Non-Commercial License (http://creativecommons.org/ licenses/by-nc/3.0/), which permits unrestricted, non-commercial use, distribution and reproduction in any medium, provided the work is properly cited. 